\title{
EFFECT OF DELAYED INTERMITTENT CATHETERISATION ON KIDNEY FUNCTION IN SPINAL CORD INJURY PATIENTS-A LONG-TERM FOLLOW-UP STUDY
}

\author{
By Rosemary Lindan, M.D. and Virginia Bellomy, R. N. \\ Infectious Diseases Unit, Cuyahoga County Hospitals, Highland View, \\ Cleveland, Ohio 44I22, U.S.A.
}

IN Britain, intermittent urethral catheterisation of patients with spinal cord lesions in commonly instituted from the time of injury (Guttmann \& Frankel 1966). In the U.S.A. this is not, as yet, so. Such patients in the U.S.A. are admitted to general hospitals following injury, and routinely have Foley catheters inserted at that time. These catheters are left in for variable periods of time, sometimes permanently. Indications for their removal usually depend upon clear signs of adequate detrusor function after a short trial period without a catheter.

In 1969 we started intermittent catheterisation for spinal cord injured patients following their admission to Highland View Hospital for rehabilitation, several weeks or months after their injury. The methods used and the early success of the approach have already been reported (Lindan \& Bellony, I97I). We now have follow-up studies up to five years on two comparable groups (A and B) treated by the traditional methods (group A, 'Controls') and by intermittent catheterisation (group B, 'Experimental') in our hospital. From these we can assess the long-term effects of intermittent catheterisation on the urinary tract functions, even when this method is instituted some time after the original injury.

\section{METHODOLOGY}

SuBjeCTs. One hundred male patients between the ages of 15 and 57 years with an average age of 33 years were studied. There were 50 patients in each group and these were matched for age at time of injury, length of interval between injury and admission to Highland View, and length of follow-up study (fig. I). There was a total of 58 quadriplegics and 42 paraplegics. The ratio of quadriplegics to paraplegics could not be matched in the two groups so that there were rather more quadriplegics in the control group. However, there were approximately the same number of upper motor neurone lesions and lower motor neurone lesions in the two groups (Table I).

\section{ROUTINE MANAGEMENT OF THE URINARY TRACT}

All patients in both groups were infected and wearing Foley catheters at the time of admission to Highland View, and all were given an initial course of specific antibiotic therapy at that time.

Following treatment of the initial infection all patients were placed on a 'suppressive' medication, usually mandelamine and ascorbic acid, occasionally 
Group B
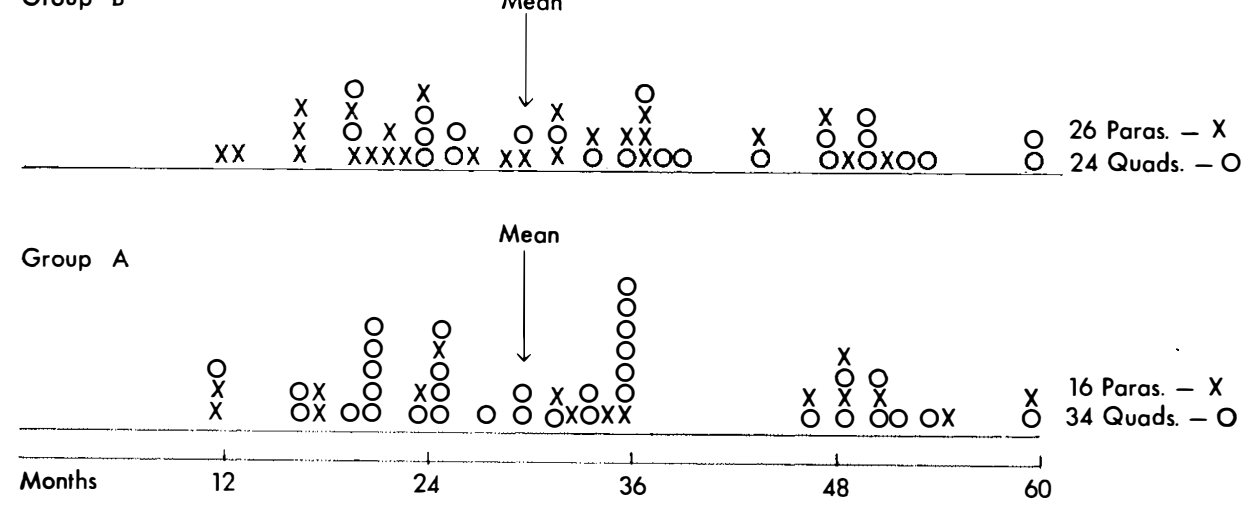

FIG. I

Follow-up periods, in months, of control group (A) and intermittently catheterised group (B).

\section{TABLE I}

Neurological lesions and type of neurogenic bladder function in group (A) and group (B)

\begin{tabular}{|l|c|c|}
\hline & $\begin{array}{c}\text { Group A } \\
\text { (controls) }\end{array}$ & $\begin{array}{c}\text { Group B } \\
\text { (interm. cath.) }\end{array}$ \\
\hline Paraplegic & I6 & 26 \\
Quadriplegic & 34 & 24 \\
\hline UMN & 39 & 35 \\
LMN & 5 & 5 \\
MMN & 6 & IO \\
\hline
\end{tabular}

small doses of nitrofurantoin or nalidixic acid, and rarely on small doses of a sulfonamide drug. When subsequent infections occurred, either with or without fever, specific antibacterial therapy was given in full dosage until the infections cleared. All patients when discharged from Highland View had sterile urines, or insignificant numbers of pseudomonas, or candida organisms only, on culture.

All patients were supplied with 'suppressive' medication at the time of discharge and recommended to continue taking this indefinitely. Nine patients in control group A, and 20 in the experimental group B, stopped taking it before the next clinic visit and took no antibacterials, except when prescribed for specific incidents of infection.

All catheterisations, in both groups, were carried out according to our standard routines and techniques by technicians from the special catheter care team (Lindan, 1969).

The 50 patients in group A were managed by the traditional method of leaving the catheter out. If voiding did not occur within eight to 12 hours or if the residual volumes remained over $100 \mathrm{ml}$. over a period of two to three weeks, the 
Foley catheters were re-inserted. No sphincterotomies were performed on this group of patients. These 50 patients, therefore, subsequently fell into one of the following categories:

(i) Unsuccessful-discharged with permanent indwelling Foley catheters (28 patients).

(ii) Successfully weaned off the catheter (I8 patients).

(iii) Subjected to urinary diversions (four patients; two with suprapubic drainage and two with ileal conduits).

The time interval from injury to successful catheter removal for the 18 patients ranged from four weeks to five years with an average of 18 months.

The patients in the 'experimental' group B, who were managed with intermittent catheterisation, were voiding independently from one to six months after injury (average three months) and had intermittent catheterisation for periods of two to 70 days (average I I days). Four of them required sphincterotomies.

The relative merits of these two methods were assessed by comparing groups $\mathrm{A}$ and $\mathrm{B}$ with respect to $(a)$ urinary infections, $(b)$ calculus formation and $(c)$ level of renal function.

(a) Urinary infections were assessed both by routine cultures performed at weekly intervals during the hospital stay, and at every regular three monthly visit to the Spinal Cord Injury Clinic after discharge, and by history of febrile episodes of urinary tract infections while in the hospital and at home.

(b) Calculus formation was assessed by flat plate X-rays of the abdomen every three months.

(c) Renal function was assessed by (i) the level of serum creatinine, (ii) the presence and degree of proteinuria and (iii) examination of the urine sediment for tubular cells and granular casts, performed weekly while in the hospital and at every clinic visit.

During follow-up, proteinuria could only be tested for by a 'dipstik' technique, so that an increase in proteinuria was taken as being a rise of $I+$ or more in specimens of the same specific gravity.

All differences between the findings in the two groups were tested for significance by the $t$-test and were considered 'statistically significant' if at a level of $0 \cdot$ I per cent or better.

\section{RESULTS}

Incidence of Urinary Infections in Groups $A$ and B. The number of patients found to have frank urinary infections (WBC $>20 / \mathrm{HPF}$ and bacteria $>\mathrm{IO}^{5} / \mathrm{ml}$.) either with or without fever and the average number of such episodes per year of follow-up are shown in Table II, from which it can be seen that both the number of patients suffering infections and the average episodes per year of follow-up were significantly lower in group B than in group A, as was the consumption of antibacterial drugs (fig. 2).

Incidence of Urinary Calculi in Groups A and B. It should be noted that all patients who developed calculi, except one, developed them after discharge from the hospital. The incidence of urinary calculi among patients in the two groups can be seen in Table III. It is statistically significant that more patients 
TABLE II

Urinary infection rates among patients in control group (A) and intermittently catheterised group (B)

\begin{tabular}{|c|c|c|c|c|}
\hline \multirow{2}{*}{ Group } & \multirow{2}{*}{$\begin{array}{l}\text { No. of } \\
\text { patients }\end{array}$} & \multicolumn{2}{|c|}{$\begin{array}{l}\text { Patients developing } \\
\text { urinary infections }\end{array}$} & \multirow{2}{*}{$\begin{array}{l}\text { Total of } \\
\text { patients who } \\
\text { developed inf.s } \\
\text { episodes }\end{array}$} \\
\hline & & O Fever & + Fever & \\
\hline A & 50 & $\begin{array}{c}44 \\
\text { (av. } 3.9 \\
\text { per patient } \\
\text { /year) }\end{array}$ & $\begin{array}{c}3^{6} \\
\text { (av. I·3 } \\
\text { per patient } \\
\text { /year) }\end{array}$ & $\begin{array}{c}45 \\
(90 \%)\end{array}$ \\
\hline B & 50 & $\begin{array}{c}26 \\
\text { (av. } 0 \cdot 7 \\
\text { per patient } \\
\text { /year) }\end{array}$ & $\begin{array}{c}\text { II } \\
\text { (av. } 0.5 \\
\text { per patient } \\
\text { /year) }\end{array}$ & $\left(\begin{array}{c}3 \mathrm{I} \\
(62 \%)\end{array}\right.$ \\
\hline
\end{tabular}

\section{TABLE III}

Relationship between urinary infections and calculus formation in control group (A) and intermittently catheterised group (B)

\begin{tabular}{|c|c|c|c|}
\hline Group & $\begin{array}{c}\text { Total number } \\
\text { of patients with } \\
\text { urinary infections }\end{array}$ & $\begin{array}{c}\text { Patients with } \\
\text { urinary infections } \\
\text { but no stones }\end{array}$ & $\begin{array}{c}\text { Patients with } \\
\text { urinary infections } \\
\text { and stones }\end{array}$ \\
\hline A & 45 & $\begin{array}{c}26 \\
(57 \cdot 8 \%) \\
26\end{array}$ & $\begin{array}{c}19 \\
(42 \cdot 2 \%) \\
(83.9 \%)\end{array}$ \\
B & $3 \mathrm{I}$ & $(\mathrm{I} 6 \cdot \mathrm{I} \%)$ \\
\hline
\end{tabular}

in group A developed urinary calculi than those in group B. The close relationship between calculus formation and urinary infection is that all patients who had stones also had urinary infections. On the other hand, not all infected patients developed stones, and in fact the majority of infected patients in both groups had no calculi up to the end of follow-up period included in this paper. However, I4 of the I9 patients in group A with calculi were still wearing retention catheters. The other five did not have their Foley catheters removed until an average of I6 months post injury (range 7-24 months) against an average of nine months for other patients in group A and three months for patients in group B. From this, it would seem that a major factor in stone formation, in addition to infections, appears to have been the long-continued presence of a balloon catheter in the bladder. One might expect then, that with longer follow-up of infected patients, particularly of those wearing balloon catheters, the larger the percentage in the 

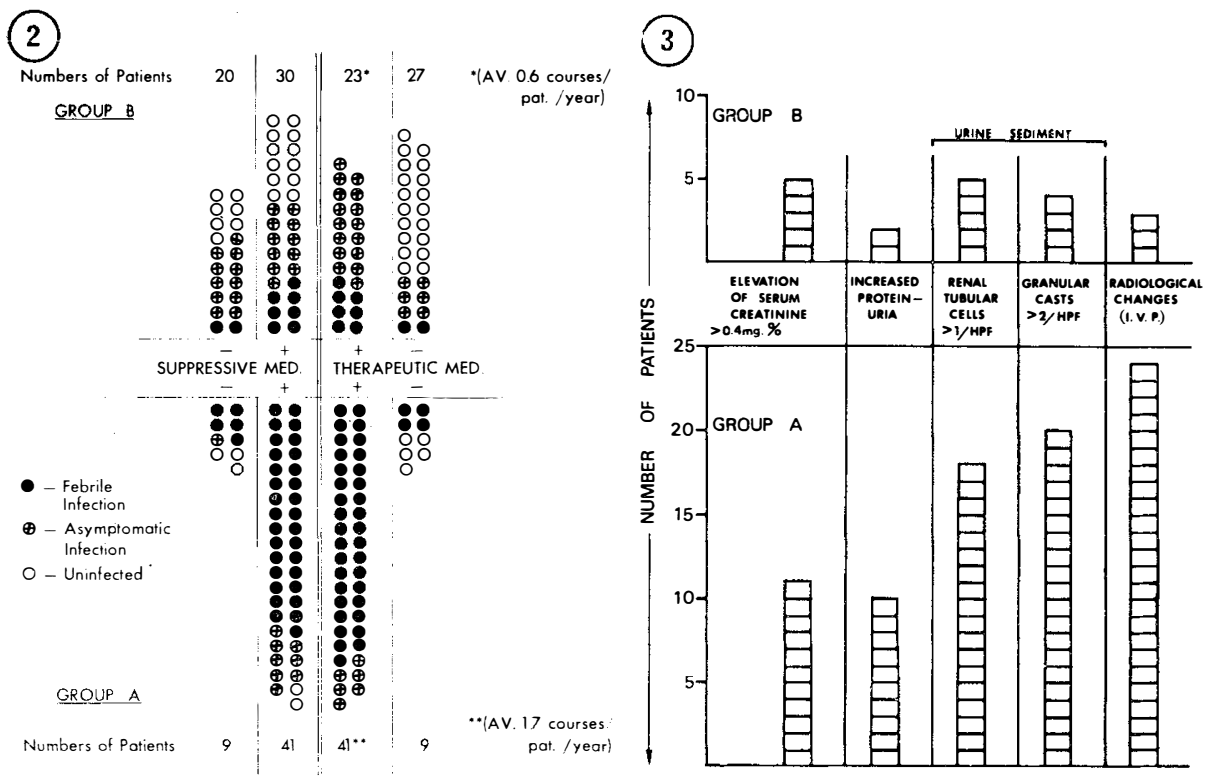

FIG. 2

Relative consumption of antibacterial drugs by patients in control group (A) and intermittently catheterised group (B).

FIG. 3

Incidence of parameters of deteriorated renal function in control group (A) and intermittently catheterised group (B).

group who would develop stones. However, this was not borne out up to the time of follow-up in our series, since nearly all the stones had formed within one year of discharge from Highland View. There are obviously other factors involved, such as $\mathrm{pH}$ and calcium content of the urine, as well as the type of infecting bacteria.

Deterioration of Renal Function in Groups A and B. Renal function was assessed in patients on admission, shortly before discharge and at varying intervals during the follow-up period, as described in the section on methodology.

Any deterioration of function was assessed by comparison of the admission values with those obtained later. The parameters used and the incidence of reduced function in the two groups are shown in Figure 3. Again it is evident that the incidence of deteriorated renal function is significantly lower in the intermittently catheterised group. Changes in the intravenous pyelograms, indicative of pyelonephritis, hydronephrosis or vesico-ureteral reflux, and the presence of granular casts in the sediment, were the major abnormalities detected among patients in group A. There is no striking predominance of any particular abnormality among patients in group B. It has been previously pointed out that single indicators of reduced renal function are unreliable and the accuracy increases with the number of tests performed (Lindan et al., I972; Price \& Newman, 1972). 

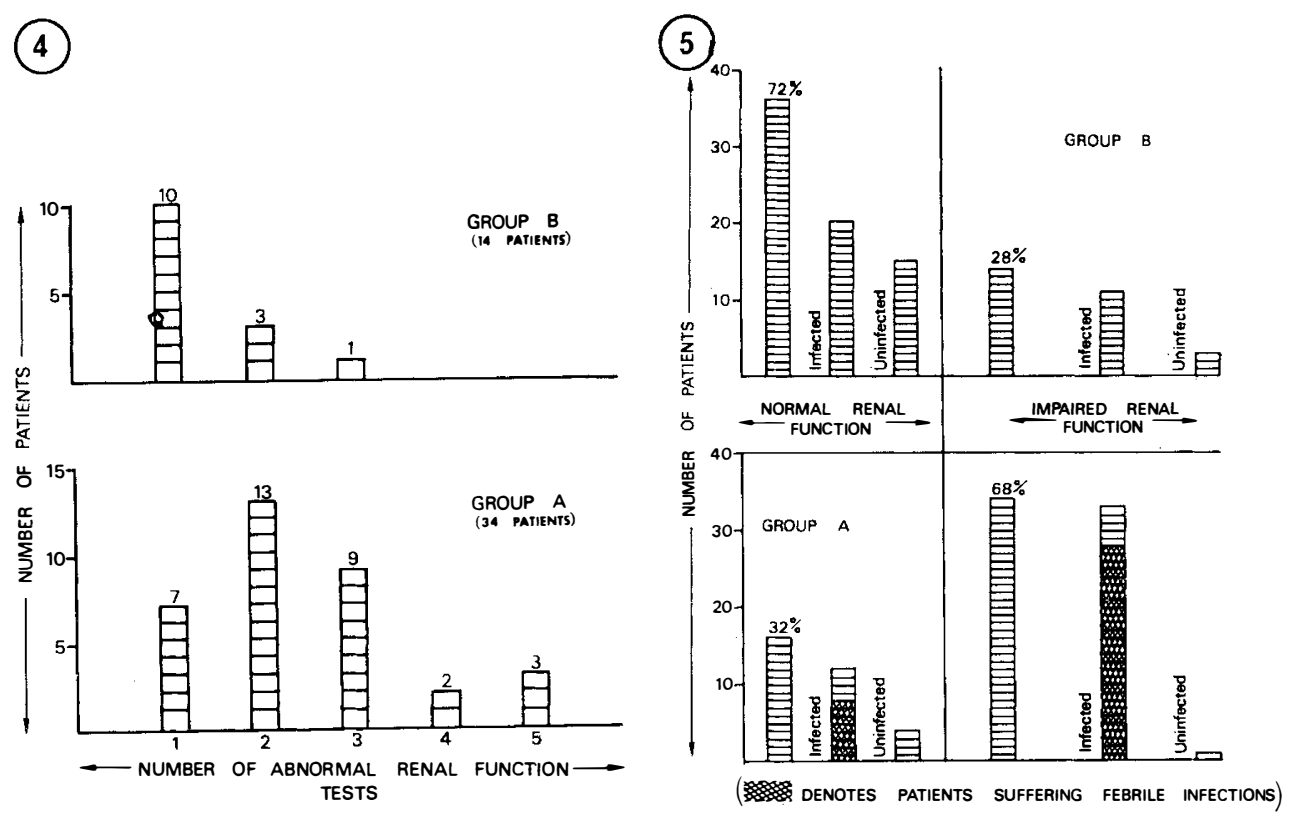

FIG. 4

Incidence of patients showing impairments of one or more parameters of renal function.

FIG. 5

Incidence of impaired renal function and its relationship to urinary tract infections in control group (A) and intermittently catheterised group (B).

In this respect it is noteworthy that the majority of patients with abnormal renal function tests in group A showed deterioration in two or more parameters, while in group B the majority showed deterioration in one parameter only (fig. 4).

There was a high correlation of urinary infections, particularly febrile infections, with reduction of renal function in both groups (fig. 5).

\section{SUMMARY AND CONCLUSIONS}

It is inequivocally demonstrated by these results that intermittent catheterisation for the removal of balloon catheters is beneficial over the long term in preventing repeated urinary infections and stone formation and in preserving renal function in spinal cord injury patients even when it is instituted weeks or months following the injury. The presence of bladder infections until this time do not necessarily indicate a poor prognosis. Intermittent catheterisation both can be, and should be, instituted as soon as possible after the spinal cord injury patient with an indwelling catheter arrives in the rehabilitation unit.

Acknowledgements. We would like to acknowledge our indebtedness to Dr. Alvin Freehafer, Chief of Orthopedic Surgery at Highland View Hospital for his help and encouragement in studying the patients on the Spinal Cord Injury Service, and to Josephine Patterson for the illustrations. 


\section{REFERENCES}

Guttmann, L. \& Frankel, H. (1966). The value of intermittent catheterization in the early management of traumatic paraplegia and tetraplegia. Paraplegia, 4, 63-84.

Lindan, R. \& Bellomy, V. (I97I). The use of intermittent catheterization in a bladder training program: Preliminary report. F. Chron. Dis. 24, 727-735.

LindAN, R. (1969). The prevention of ascending, catheter-induced infections of the urinary tract. F. Chron. Dis. 22, $32 \mathrm{I}-330$.

Lindan, R., Post, R. S., Bernier, G. M. \& SAlazar, R. (I972). A low molecular weight protein $\left(\mathrm{B}_{2}\right.$-microglobulin) and renal disease in spinal cord injury patients. Paraplegia, Io, 244-247.

PRICE, M. \& NEWMAN, E. (1974). Factors associated with deterioration of kidney function in patients with spinal cord injury. F. Am. Med. Wom. Assoc. 29, 67-70. 